\title{
Perceptions Of Accountants: What Are They After Enron And WorldCom?
}

Gwendolen B. White, (E-mail: gwhite@bsu.edu), Ball State University Michael J. White, Ball State University

\begin{abstract}
College students evaluated accountants, along with five other occupations, using Osgood's semantic differential model. This model of semantic meaning captures three semantic dimensions evaluation, potency, and activity. Students gave accountants high ratings on the evaluation (good bad) dimension, but they rated accountants much lower on the potency (deep - shallow) dimension and activity (fast - slow) dimension. The results are discussed in terms of the implications for the future of the accounting profession.
\end{abstract}

\section{INTRODUCTION}

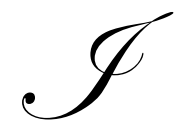

$\mathrm{n}$ order for accountants to perform their role in the financial world, they must be perceived to be trustworthy. No doubt most accountants are and have always been trustworthy, but their perceived trustworthiness has been called into question by recent financial scandals involving accountants. Recent financial scandals involving accountants (e.g., Enron, WorldCom, and Tyco) have affected the public's perception of the accounting profession. In 2002, a Gallup poll indicated that the accounting profession's positive ratings were $31 \%$ - a 16\% drop from the $47 \%$ positive rating received in 2001 before the collapse of Enron (AICPA, 2005). Not only had positive ratings declined, negative ratings had increased. Negative ratings before the fall of Enron in 2001 were $8 \%$ and increased to $31 \%$ in 2002 (AICPA, 2005). The implications of such low positive ratings and high negative ratings have had a dramatic impact on the profession. The major one is increased regulation with the passage of the The Sarbanes-Oxley Act of 2002.

History shows that monumental financial scandals usually result in increased public and legislative scrutiny of business activity. The accounting profession generally considers increased regulation as unwanted and undesirable, but increased regulation is not without its benefits. While increased legislation reduces the ability of the accounting profession to police itself, new legislation often creates more employment for accountants. For example, the stock market crash of 1929 was an impetus for the Securities and Exchange Acts of 1933 and 1934. Prior to the 1930's, corporations were not required to submit financial reports to the government or shareholders. These laws had substantial effects on the accounting profession. For example, the Securities and Exchange Act of 1934 required publicly held companies to report specific financial information and to have it audited. This greatly increased work available to accountants. The more recent Sarbanes-Oxley Act of 2002 was in response to contemporary financial scandals. It, too, has had far reaching financial consequences. The Sarbanes-Oxley Act requires enhanced standards for auditor independence, corporate responsibility, and Boards of Directors. The Act also created the Public Company Accounting Oversight Board (PCAOB) to oversee the activities of the auditing profession. Thus, the accounting profession has to contend with more regulation to bolster public trust in their work that involves providing quality assurance to the public. 
Substantial and sustained erosion of trust would be a major blow to a profession that requires the honoring of public trust in its code of professional conduct. Section 53, Article II of the AICPA's Principles of Professional Conduct (AICPA, 2006) states, "Members should accept the obligation to act in a way that will serve the public interest, honor the public trust, and demonstrate commitment to professionalism." Maintaining the public's trust is necessary for accountants to meet their obligation to society. Positive perceptions of the accounting profession are essential if accountants want to continue in their role as providers of quality assurance in corporate statements. One of the longer-term consequences might be that accountants would no longer be permitted to perform audits of financial statements.

Perceptions about accountants will also influence who is attracted to the profession. An examination of the history of accounting enrollments since the 1970s reveals how much enrollments have varied over the last 36 years. The 1970s were a period of growth. During this time, the growth in accounting degrees awarded ranged from $12 \%$ to $20 \%$ (AICPA, 2005a). The growth rate slowed considerably in the early 1980's, and by the mid 1980's enrollments were declining. There were modest increases and decreases in the 1990's. Since 2000 there has been an upward trend in enrollments. Total enrollments in accounting programs increased 19\% for the four-year period 2000-2004 (AICPA, 2005a). During the 2003-2004 academic year, 40,400 students received Bachelor's degrees ( $9 \%$ above the previous year) and 13,300 students received Master's degrees (5.4\% above the previous year).

The increased interest in accounting as an academic major could ironically be due to accountants' role in recent financial scandals. As politicians and actors are reported to say, "Any publicity is good publicity." The notoriety that accountants have received has, perhaps, made the field of accounting more cognitively salient as a possible profession for college students (Quinn, Macrae, \& Bodenhausen, 2003). In addition, the demand for accountants has dramatically increased with the passage of the Sarbanes-Oxley Act. The new law has increased the demand for accounting firms to help companies comply with the law. To meet this new demand, public accounting firms hired 17\% more new accounting graduates in 2004 than in 2003 (AICPA, 2005a).

The recent steady rise in enrollments in accounting programs and the increase in the hiring of graduating accountants is welcome news for the accounting profession. Nonetheless, the changes in enrollments need to be explored. Are these temporary changes that reflect only supply and demand issues? Are students deciding to enter the profession just to get a job? Is it a job that they hold in high regard or is it something that will do till something better comes along. How do current students perceive accountants? The answers to these questions are important for the stability of recruitment to the profession. This study will begin to answer some of them.

Using Osgood semantic differential theory of attitude assessment (Osgood, May, \& Miron, 1975; Snider \& Osgood, 1969), this study examines how college students view accountants and five other occupations (Attorney, CEO, Financial Analyst, Lobbyist, and Politician). Two of these occupations, CEO and Financial Analyst, were chosen because of their direct relevance to the business community. Their inclusion permits us to compare how they are perceived with how accountants are perceived. The occupations Attorney, Lobbyist, and Politician were selected because they consistently receive low rankings for integrity and adherence to high ethical standards. Evidence of the low esteem in which attorneys are held can be seen in the results of a Gallup poll taken in 2004, where only 18\% of respondents rated attorneys as very high or high on honesty and ethical standards (CBS News, 2004). This is consistent with previous polls taken over the last 30 years (Sourcebook of Criminal Justice Statistics, 2005). According to a 2004 Gallup poll, only $10 \%$ of respondents rated Congressmen as very high or high on honesty and ethical standards (CBS News, 2004). In a Los Angeles Times/Bloomberg Poll taken January 22-25, 2006, 64\% of Americans rated ethics and honesty in Congress as "not so good/poor" (Public Citizen, 2006). Lobbyists also do not fare well with the American public (Public Citizen, 2006). In a poll taken January 4-6, 2006, by the Pew Research Center for the People, $81 \%$ of Americans believed it is common for lobbyists to bribe members of Congress (Public Citizen, 2006). In another poll conducted by Brasswood Research on January 28-29, 2006, 61\% had an unfavorable opinion of lobbyists (Public Citizen, 2006). Including these occupations permits us to compare accountants with occupations that have not maintained the public's trust. 
Three categories of adjectives (evaluation, potency, and activity) are typically used with the semantic differential model. These dimensions reflect a multi-dimensional semantic space within which different objects can be plotted based on the meanings assigned to them. Will accountants be plotted within this space closer to low regarded occupations or to more highly perceived occupations?

\section{METHOD}

\section{Participants}

Fifty-four undergraduate business majors (39 men, 15 women) served as participants. The mean age was 20.4 $(\mathrm{SD}=1.13)$. Students reported their ethnicity as follows: Caucasian American $(85.2 \%)$, African American $(11.1 \%)$, Asian American (1.9\%), and Other (1.9\%). Nine majors were represented: accounting (11.1\%), finance (5.6\%), marketing (13.0\%), management (3.7\%), economics (3.7\%), entrepreneurship (9.3\%), information systems (5.6\%), business administration (3.7\%), and other (22.2\%). They indicated their class standing to be: freshman (1.9\%), sophomore $(61.1 \%)$, junior (31.5\%), senior (3.7\%), and other (1.9\%). Students earned extra credit, research participation points according to plans approved by their respective course instructors.

\section{Materials}

A chef and a fast-food "burger-flipper" are both occupations involving food preparation, but they clearly have different meanings. One means of assessing such connotative differences is through the semantic differential (Osgood, May \& Miron, 1975; Osgood, Suci, \& Tannenbaum, 1957). This measurement instrument is derived from factor analyses of thousands of adjective pairs across several cultures and linguistic groups. The most consistent finding from this research is that three dimensions account for most of the variance in affective meaning: evaluation, potency, and activity.

Adjective pairs selected for use in this study reflect these three major affective dimensions of meaning. Using Osgood et al.'s (Osgood, May \& Miron, 1975; Osgood, Suci, \& Tannenbaum, 1957 ) atlases, 19 adjective pairs were selected: 12 for evaluation, four for potency, and three for activity. Approximately $35 \%$ of the total variance associated with meaning involves evaluation; hence, most of the adjective pairs were associated with evaluation. Evaluation may be thought of as a measure of "goodness." The most important of the adjective pairs associated with this dimension, good - bad, has a factor loading of approximately .90 and is a nearly "pure" measure of evaluation. The other evaluation pairs were honest - dishonest, objective - subjective, unbiased - biased, careful - negligent, competent - incompetent, fair - unfair, trustworthy - untrustworthy, truthful - untruthful, professional - unprofessional, skilled - unskilled, and incorruptible - corruptible. Although presented here in positive to negative order, the connotative order of pairs was randomized before presentation to participants. Several of these adjectives (i.e., objective, competent) are taken from the Statement on Auditing Standards that describes a CPA's qualities. The potency dimension accounts for about seven percent of total variance; strong - weak has a factor loading of approximately .60 on this dimension. It thus may be considered to be a measure of power or strength. Other potency adjective pairs were: deep - shallow, aggressive - unaggressive, and assertive - unassertive. The activity dimension accounts for only slightly less of the total variance in meaning, $6 \%$, than potency. It may be thought of as a measure of how engaged persons in the different occupations are. Fast - slow has a factor loading of approximately .70 with activity. Two other adjective pairs define activity: sharp - dull and active - passive.

\section{Procedure}

Participants were to consider the occupation listed on each of the six response sheets. They then rated the occupation using the 19 adjective pairs, which were presented as end points of an unlabeled seven-point continuum. Participants selected the point on the continuum for each adjective pair that best represented their perception of the occupation under consideration. Scores for evaluation, potency, and activity were calculated by taking the mean of their responses to the adjectives associated with each dimension. A higher score reflects a more positive rating. After rating the occupations, students provided their sex, age, academic major, educational status, and ethnicity. 
Participants thus rated six occupations, a within-subjects factor, using the semantic differential scales. The six occupations were presented in one of four randomly determined orders, which along with participant's sex, were treated as between-subjects factors in subsequent analyses.

\section{RESULTS}

Reliability analyses of the three semantic differential scales indicated that they had excellent to good reliability based on Cronbach's alpha; values were: Evaluation (.93), Potency (.74), and Activity (.75). Besides the participant's sex, the four different occupation presentation orders were included as methodological checks. No hypotheses for either sex or order were made. A multivariate analysis of variance using the three semantic differential measures as repeated dependent variables showed neither main nor interaction effects for sex or order. The same analysis, however, produced a significant multivariate effect for the within-subjects variable, occupation type. Based on the Pillai-Bartlett trace, a significant multivariate effect was observed for occupation, $F(5,42)=10.53, p<.001$, and for semantic differential measure, $F(2,45)=29.30, \quad p<.001$. Thus, evaluations differed according to the occupation considered and according to the scale used for assessment. Evaluations did not differ according to sex of evaluator or order of presentation. Followup univariate ANOVAs for each of the dependent variables produced similar results; neither sex nor order nor their interaction was significant. Main effects for occupation were obtained for evaluation, $F(5,260)=59.77, p<.001$, potency, $F(5,260)=10.43, p<.001$, and activity, $F(5,260)=6.71, p<$ .001 .

Table 1 contains the average responses to the occupations. As may be seen, CPA receives the highest mean evaluation of any occupation. In contrast, CEO receives the highest rating for potency, followed closely by Attorney. CPA is next to the lowest occupation for potency. Attorney is the highest rated occupation for activity, while CPA is next to the bottom on this scale.

Table 1

Semantic Differential Scale

\begin{tabular}{lcccccc}
\hline & \multicolumn{2}{c}{ Evaluation } & \multicolumn{2}{c}{ Potency } & \multicolumn{2}{c}{ Activity } \\
Occupation & Mean & SD & Mean & SD & Mean & SD \\
CPA & 5.79 & .59 & 4.87 & 1.01 & 4.99 & 1.20 \\
Financial Analyst & 5.41 & .79 & 5.12 & 1.02 & 5.14 & 1.18 \\
Attorney & 4.59 & .78 & 5.72 & .74 & 6.03 & .79 \\
CEO & 4.92 & .78 & 5.77 & .78 & 5.61 & 1.05 \\
Politician & 3.76 & .94 & 4.83 & 1.03 & 4.91 & 1.22 \\
Lobbyist & 4.13 & .85 & 5.03 & 1.04 & 5.19 & 1.14 \\
\hline
\end{tabular}

Note. $n=54$

\section{DISCUSSION}

The results of the current study indicate that accountants were rated highly on the evaluation (goodness) dimension but not on the potency (power) or activity (engagement) dimensions. The results from the evaluation dimension of this study are consistent with the results of a 2005 Gallup poll taken with members of the business community (AICPA, 2005). Accountants were given a $45 \%$ positive rating. This is good news for the accounting profession. They are perceived as having more trustworthiness and honesty than any of the six occupations rated. Yet a more interesting result is how accountants were rated on potency and activity. 
Although they are seen as being very trustworthy, competent, and honest, etc., they do not appear to have as much impact relative to CEOs and attorneys. They are good but not powerful or engaged. What are the potential implications for the profession? From the perspective of ethics, this may be extremely troublesome for a profession that wants to hold their own in meeting their obligations to society. It is unacceptable for accountants to be perceived as good, but lacking in power to hold their own with other, less honest business practitioners.

These results are intriguing. One of the limitations of this study, however, is the inability to generalize these results. The sample size is relatively small and only includes one university. Before recommendations are made to try to improve the perceptions about potency and activity, more research needs to be conducted with other university students and the business community. If similar results are found, the accounting profession should consider ways to increase the perception of a strong and engaged profession. The best and most direct way to do this would be to lead in pursuing misleading practices committed by others.

\section{REFERENCES}

1. AICPA (2005). Gallup Survey Shows Accounting's Image Still Rising, The CPA Newsletter, November, 2005, Retrieved May 21, 2006, from www.aicpa.org/pubs/cpaltr/nov2005/gallup.htm

2. AICPA (2005a). 2005 Supply/Demand Report Shows Continued Increase in Accounting Graduates, Employment Up, The CPA Newsletter, October, 2005, Retrieved May 21, 2006, from www.aicpa.org/pubs/cpaltr/oct2005/supply.htm

3. AICPA (2006). AICPA Code of Professional Conduct, ET Section 53., Retrieved May 21, 2006, from www.aicpa.org/about/code/et_section_53_article_ii_the_public_interest.html

4. CBS News (2004). Nurses Top List for Honesty, Retrieved May 21, 2006, from www.cbsnews.com/stories/2004/12/08/health/webmd/main659857.shtml

5. Osgood, C. E., May, W. H., \& Miron, M. S. (1975). Cross-cultural universals of affective meaning. Urbana, IL: Illinois.

6. Osgood, C. E., Suci, G. J. \& Tannenbaum, P. H. (1957). The measurement of meaning. Urbana: University Illinois Press.

7. Public Citizen (2006). Recent Public Opinion Polls on Ethics in Government, Congress Watch, February 2006, Retrieved May 21, 2006, from www.citizen.org/congress/govt reform/ethics/congethics/articles.cfm? ID $=14945$

8. Quinn, K. A., Macrae, C. N., \& Bodenhausen, G. V. (2003). Stereotyping and impression formation: How categorical thinking shapes person perception. In M. A. Hogg \& J. Cooper (Eds.), Sage handbook of social psychology (pp. 87-109). Thousand Oaks, CA: Sage Publications.

9. Snider, J. G. \& Osgood, C. E. (Eds.). (1969). Semantic differential technique: A sourcebook. Chicago: Aldine.

10. Sourcebook of Criminal Justice Statistics (2005). Respondents' ratings of the honesty and ethical standards of lawyers, United States, Selected years 1976-2005, Retrieved May 21, 2006, from www.albany.edu/sourcebook/pdf/t2182005.pdf 
NOTES 